\title{
DEVELOPMENT OF SMAP (SOIL MOISTURE ACTIVE AND PASSIVE) FREEZE/THAW ALGORITHMS ADAPTED FOR THE CANADIAN TUNDRA.
}

\author{
P. Kalantari ${ }^{1}$, M. Bernier ${ }^{2}$, Senior Member, K.C. McDonald ${ }^{3}$, Senior Member, and J. Poulin ${ }^{4}$ \\ 1, 2, 4: INRS, Centre Eau Terre Environnement \\ 3: CUNY Environmental Crossroads Initiative and CREST Institute
}

\begin{abstract}
This study is conducted in the framework of the NASA SMAP mission. The frozen soil mapping would certainly be improved by using the future NASA SMAP instruments which include both a Radiometer and a SAR operating at Lband. SMAP will have the ability to sense the soil conditions through moderate land cover. The radiometric accuracy, the better spatial resolution $40 \mathrm{~km}$ passive and 3 $\mathrm{km}$ active, and the global coverage of SMAP will make possible the monitoring of the seasonal $\mathrm{F} / \mathrm{T}$ cycle at a regional scale. The objective of this study is to develop algorithms to track the seasonally $\mathrm{F} / \mathrm{T}$ over the Tundra and the Boreal Forest. The experimental site is located in Northern Quebec (Nunavik) in Canada. We use available SMOS data from Environment Canada and in situ temperature and soil moisture data measured in different environments of the tundra and taiga.
\end{abstract}

Index Terms - SMAP, SMOS, Freeze/Thaw, Nunavik

\section{INTRODUCTION}

The seasonal Freeze/Thaw (F/T) cycle is a major phenomenon in the climate system and plays an important role in ecosystem functioning [2] by influencing the rate of photosynthesis and respiration of the vegetation [11], reducing evaporation, reducing the penetration of water into the soil and altering surface runoff $[2,11]$. Boreal and arctic regions form a complex land cover mosaic where vegetation structure, condition and distribution are strongly regulated by environmental factors such as soil moisture and nutrient availability, permafrost, growing season length and disturbance. In these seasonally frozen environments, the growing season is determined primarily by the length of the non-frozen period. Variations in both the timing of spring thaw and the resulting growing season length have been found to have a major impact on terrestrial carbon exchange and atmospheric $\mathrm{CO} 2$ source/sink strength in boreal regions $[13,7,8$, and 14].

Microwave sensors on board satellite are well adapted tools to monitor the $\mathrm{F} / \mathrm{T}$ cycle over the Boreal and Arctic regions of North America [8, 14]. Frozen soil behaves like dry soil at the microwave frequencies. Previous F/T cycle studies with low spatial resolution passive microwave sensors like
SSMI [14] or AMSR-E [10, 12] have given encouraging results. Further, active microwave sensors (SAR) operating in $\mathrm{Ku}, \mathrm{C}$ or $\mathrm{L}$ band can determine the state of the soil surface, either frozen or thawed $[4,5]$. Both RADARSAT-2 C-band (5.4 GHz) data [5] and JERS L band data [3] have given interesting results. The potential of ALOS-PALSAR $(1.4 \mathrm{GHz})$ data for $\mathrm{F} / \mathrm{T}$ monitoring is presently studied [9]. The frozen soil mapping would certainly be improved by using the future NASA SMAP (Soil Moisture Active and Passive) instruments which include both a Radiometer and a SAR operating at L-band (1.40-1.41 GHz). In fact, SMAP will be able to monitor the frozen soil because of its capability to make coincident measurements of surface emission and backscatter, and with its ability to sense the soil conditions through moderate land cover. The launch of the SMAP mission is scheduled for 2014 or 2015. The radiometric accuracy, the better spatial resolution $40 \mathrm{~km}$ passive and $3 \mathrm{~km}$ active, and the global coverage of SMAP will make possible a systematic updating of frozen ground maps and monitoring the seasonal $\mathrm{F} / \mathrm{T}$ cycle at a regional scale.

Then, the main objective of this study is to develop and validate algorithms to monitor $\mathrm{F} / \mathrm{T}$ over the Tundra and the Boreal Forest for the future SMAP mission using available time series of passive microwave and SAR L-band data. The study area is Northern Quebec (Nunavik) in Eastern Canada. The main field site is located near Umiujaq $\left(56.55^{\circ}\right.$ $\mathrm{N}, 76.55^{\circ} \mathrm{O}$ ). It is a zone of discontinuous permafrost located at the tree line. This site has been the subject of more than 20 years of study by the Center for Northern Studies (CEN).

\section{DATA USED}

\subsection{SOIL MOISTURE AND OCEAN SALINITY MISSION (SMOS)}

The European Space Agency (ESA) Soil Moisture and Ocean Salinity (SMOS) mission was launched on November 2,2009 . Providing accurate soil moisture (SM) estimation is one of its main scientific objectives. [6]. SMOS carries a single payload, an L-Band 2D interferometric radiometer in the 1.40-1.43 GHz. This wavelength penetrates well through the atmosphere, and hence the instrument probes the earth surface emissivity. Surface emissivity can then be 
related to the moisture content in the first few centimeters of soil, and, after some surface roughness and temperature corrections, to the sea surface salinity over ocean.

\subsection{IN-SITU MEASUREMENT}

We use data from the meteorological network of the Centre for Nordic Studies (CEN), but we need additional data on temperature and soil moisture in different environments of the tundra and taiga. Table 1 gives the type of land cover, soil types and geographic coordinates where the sensors are installed (Umiujaq).

\section{METHODS}

We are testing different passive microwave algorithms. In particular, we will try the approach proposed by Kim et al. [14] with SMOS L-band data (1.4 GHz) using the followed equation:

$$
\Delta T_{b p}(x, t)=\frac{\left(T_{b p}(x, t)-\operatorname{FrozRef}(x)\right)}{(\operatorname{ThawRe} f(x)-\operatorname{FrozRe} f(x))}
$$

Then, the SSM/I landscape F/T status is determined using the following formulas, which define respectively thawed and frozen landscape states.

$$
\begin{aligned}
& \Delta T_{b p}(x, t)>T(x, t) \\
& \Delta T_{b p}(x, t) \leq T(x, t)
\end{aligned}
$$

The output is a dimensionless DIM binary state variable designated by zero (0) for frozen and one (1) for non-frozen conditions for each pixel. Also, we will test both emissivity and brightness temperature $[1,12]$. The emissivity is derived from the brightness temperature normalized by air and atmosphere. This coefficient correlated better with the weather and the sparse vegetation.

Up to now, we carried out the brightness temperature of SMOS, the values extracted were recorded at 40 degree incident angle as SMAP.

\section{RESULTS}

\subsection{Temporal evolution of soil temperature}

Figure 1 shows the place of soil temperature sensors in Umiujaq. Figure 2 shows the soil surface temperature evolution from July 7, 2010 to the end of year 2010, near Umiujaq (Nunavik). For each 12 sensors, the decrease of soil surface temperature and then freezing and thawing dates are different due to the difference in vegetation cover (type and height), in soil texture (sand, humus) and in relief (flat, slope) as given by Table 1 .

\subsection{SMOS}

Figure 3 shows dual and crossed polarization multi-angular brightness temperature observations of SMOS images on November 2010. These brightness temperatures values are in Kelvin. According to this figure, there is a large change on November 23 for both co-polarization $\mathrm{VV}$ and $\mathrm{HH}$. In situ data (Figure 2) also shows a decrease of soil temperatures below zero degree for most sensors on November 23, 2010.

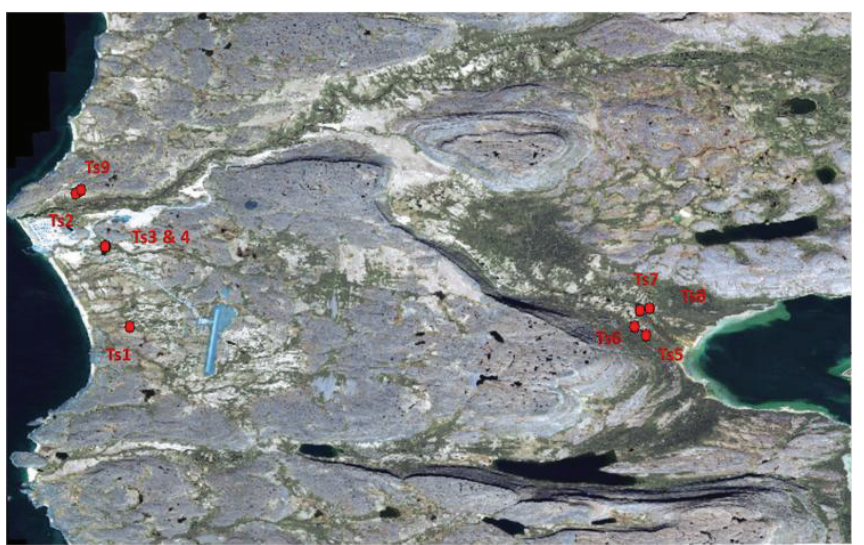

Figure 1: Brightness Temperature Sensor

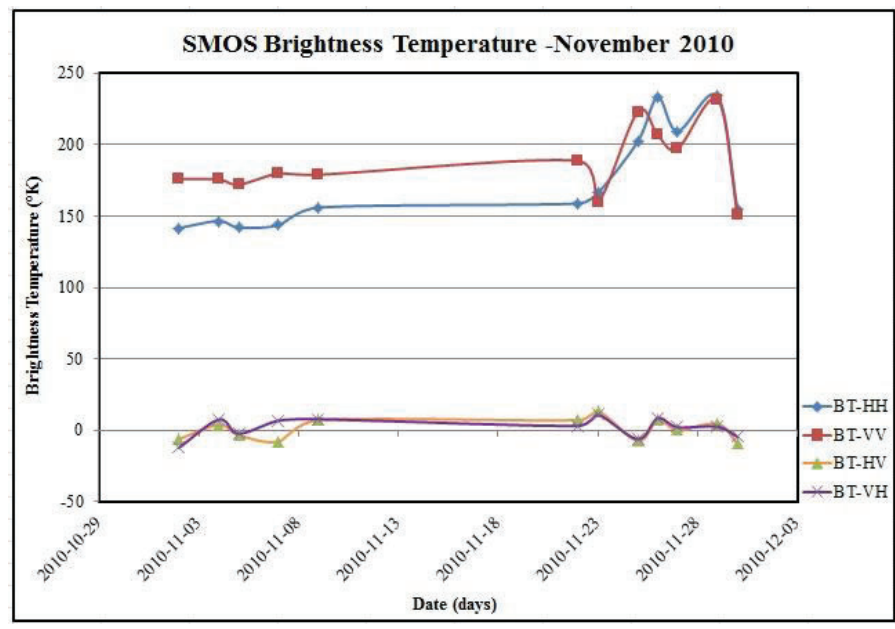

Figure 3: SMOS Brightness Temperature

\section{CONCLUSION}

Field data shows that freezing and thawing dates vary much spatially at the local scale in the tundra. Therefore, the field validation of the $\mathrm{F} / \mathrm{T}$ state maps at the regional scale will be very important. Furthermore, the algorithms to be developed should be adapted to take care of the surface subgrid-scale heterogeneity (vegetation, soil, relief) within a given pixel of a few kilometers and the different polarization. 


\section{REFERENCES}

[1] A. Royer, K. Goïta, J. Kohn, D. De Sève, "Monitoring dry, wet, and no-snow conditions from microwave satellite observations.", IEEE Geos. Rem. Sens. Letters, 7, 670-674. 2010.

[2] C. Lagacé, Développement et validation d'une approche pour faire le suivi du gel saisonnier du sol sur le bassin de la rivière $\mathrm{La}$ Grande à partir de l'utilisation conjointe d'images RADARSAT et d'images SSM/I. INRS-ETE Québec, Canada. 2000.

[3] C. Werner, U. Wegmüller, A. Wiesmann, T. Strozzi. "Interferometric Point Target Analysis with JERS-1L-band SAR Data." Gamma Remote Sensing, Switzerland. 2003.

[4] E. Rignot, J. B. Way, K. McDonald, L.Viereck, C. Williams, P. Adams, C. Payne, W. Wood, and J. Shi. "Monitoring of environmental conditions in Taiga forests using ERS-1 SAR." Remote Sensing of Environment, 49, 145-154. 1994.

[5] J. Khaldoune, Développement d'une méthode de mesure et de cartographie du gel du sol en milieu agricole à l'échelle d'un bassin versant à partir d'images radar monopolarisées, multipolarisées et polarimétriques. INRS-ETE, Québec, Canada. 2006.

[6] J.T. dall'Amico, F. Schlenz, A. Loew, and W. Mauser, "First Results of SMOS Soil Moisture Validation in the Upper Danube Catchment." Ieee Transactions On Geoscience And Remote Sensing, VOL. 50, NO. 5, MAY 2012

[7] J. T. Randerson, C. B. Field, I. Y. Fung, and P. P. Tans, "Increases in early season ecosystem uptake explain recent changes in the seasonal cycle of atmospheric CO2 at high northern latitudes." Geophysical Research Letters, 26, 2765-2768. 1999.

[8] K. C. McDonald, J. S. Kimball, E. Njoku, R. Zimmermann, and M. S. Zhao, "Variability in Springtime Thaw in the Terrestrial High Latitudes: Monitoring a Major Control on the Biospheric Assimilation of Atmospheric $\mathrm{CO}(2)$ with Spaceborne Microwave Remote Sensing." Earth Interactions, 8. 2004.

[9] K. C. McDonald, "Mapping Global Wetlands and Boreal Freeze/Thaw with ALOS PALSAR", Science Team meeting \#16 Phase 3 Kick-off, JAXA TKSC/RESTEC HQ, Tsukuba/Tokyo, October 17-21. 2011.

[10] L. A. Jones, J. S. Kimball, et al., "Satellite Microwave Remote Sensing of Boreal and Arctic Soil Temperatures From AMSR-E." IEEE Trans. Geos. and Remote Sensing, 45(7). 2007.

[11] N. V. Smith, S. S. Saatchi, and J. T. Randerson, "Trends in high northern latitude soil freeze and thaw cycles from 1988 to 2002," Journal of Geophysical Research D: Atmospheres, 109, D12101 1-14. 2004

[12] P. Kalantari, M. Bernier, and J. Poulin, "Utilisation conjointe de données de micro-ondes passives et actives pour le suivi du gel saisonnier du sol de la toundra dans le Nord du Québec.", 30ième Symp. Can.de télédétection, 22-26 juin, Lethbridge, Alberta, 12 pages. 2009.

[13] S. Frolking, , M. L. Goulden, S. C. Wofsy, S. M. Fan, D. J. Sutton, J. W. Munger, A. M. Bazzaz, B. C. Daube, P. M. Crill, J.
D. Aber, L. E. Band, X. Wang, K. Savage, T. Moore, and R. C. Harriss, "Modelling temporal variability in the carbon balance of a spruce/moss boreal forest." Global Change Biology, 2, 343-366. 1996.

[14] Y. Kim, J. S. Kimball, K. C. McDonald, and J. Glassy, "Developing a global data record of daily landscape freeze/thaw status using satellite passive microwave remote sensing. IEEE Trans." Geoscience and Remote Sensing, 49, 949-960. 2011. 
Table 1: Land Cover and the Soil Texture of each Sensor

Temperature Sensors: Umiujaq 2010-2011

\begin{tabular}{|c|c|c|c|c|c|c|}
\hline \multirow[t]{2}{*}{ \#Temperature Sensor } & \multicolumn{2}{|c|}{ GPS Coordinates } & \multirow[t]{2}{*}{ Coordinate System } & \multirow[t]{2}{*}{ Vegetation } & \multirow[t]{2}{*}{ Height/Vegetation Type } & \multirow[t]{2}{*}{ Relief/Soil } \\
\hline & $\mathbf{X}$ & $\mathbf{Y}$ & & & & \\
\hline Ts-1 & $-76,53$ & 56,54 & WGS84 & Yes & $55 \mathrm{~cm}$ & Dune \\
\hline Ts-2 & $-76,54$ & 56,55 & WGS84 & Yes & $60 \mathrm{~cm}$ & Flat Area \\
\hline Ts-3 & 411541,95 & 6266926,02 & NAD83 & Yes & Shrubs & Sand \& Hummus \\
\hline Ts-4 & 411670,27 & 6266766,11 & NAD83 & Yes & Tall Shrubs & Humus \\
\hline Ts-5 & 411670,27 & 6266766,11 & NAD83 & No & Lichen & \pm Sand \\
\hline Ts-6 & $-76,54$ & 56,56 & WGS84 & Yes & Shrubs & Sand \\
\hline Ts- 7 & $-76,54$ & 56,55 & WGS84 & No & $4 \mathrm{~cm}$ & Slope \\
\hline Ts- 8 & $-76,54$ & 56,56 & WGS84 & No & Lichen & Sand \\
\hline Ts-9 & $-76,54$ & 56,56 & WGS84 & No & Lichen & Sand \\
\hline Ts -10 & $-76,53$ & 56,54 & WGS84 & No & $0-1 \mathrm{~cm}$ & Dune \\
\hline Ts-11 & $-76,54$ & 56,56 & WGS84 & Yes & Shrubs & Sand \\
\hline Ts-12 & 411541,95 & 6266926,02 & NAD 83 & No & Lichen & Sand \\
\hline
\end{tabular}
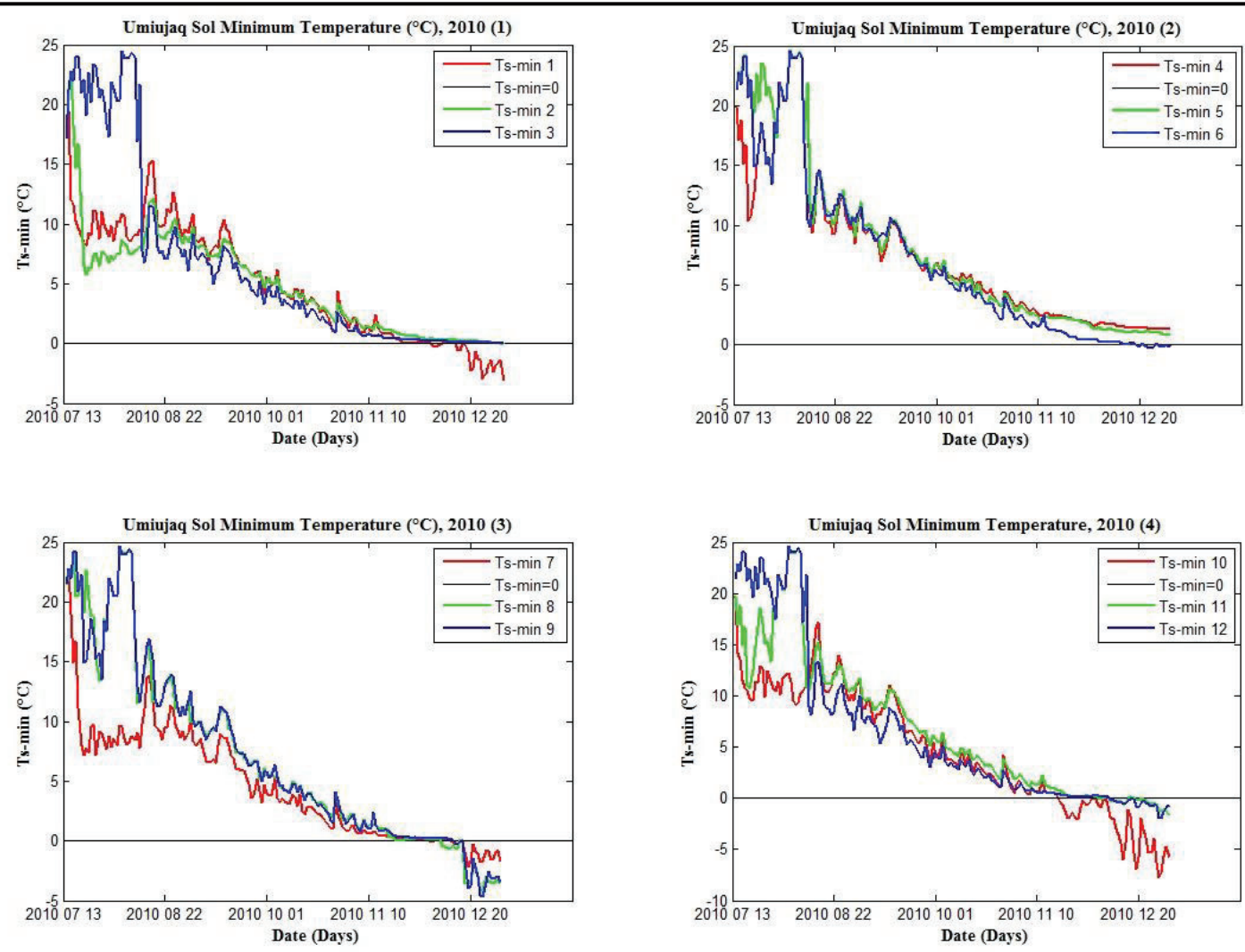

Figure 2: Soil Surface Temperature recorded by 12 different sensors in Umiujaq, 2010 